\title{
IMMUNOHISTOCHEMICAL ANALYSIS OF MAST CELL INFILTRATES AND MICROVESSEL DENSITY IN ORAL SQUAMOUS CELL CARCINOMA
}

\author{
Łukasz Pyziak ${ }^{1}$, Olga Stasikowska-Kanicka ${ }^{1}$, Marian Danilewicz ${ }^{2}$, \\ MAŁgORZATA WąGROWSKA-DANILEWICZ ${ }^{1}$
}

\author{
${ }^{1}$ Department of Nephropathology, Medical University of Lodz, Lodz, Poland \\ ${ }^{2}$ Department of Pathomorphology, Medical University of Lodz, Lodz, Poland
}

\begin{abstract}
The aim of the study was to evaluate mast cell concentration and microvessel density in perilesional and intralesional regions of oral squamous cell carcinoma (OSCC) and furthermore to assess the possible relationship between the above-mentioned parameters.

Paraffin-embedded specimens from 47 cases of OSCC and 12 cases of normal mucosa were investigated immunohistochemically with anti-CD-31 antibody to stain microvessels and anti-tryptase antibody to visualize mast cells. The degree of vascularization and mast cell infiltration was measured with an image analysis system. The study revealed considerably increased microvessel density and mast cell abundance in intralesional and perilesional regions of OSCCs in comparison to normal mucosa. There was a significant positive correlation between microvessel density and mast cell concentration in both localizations of OSCCs ( $p<0.02$, p $<0.001$, respectively), whereas a comparable correlation was not observed in normal mucosa. The obtained results suggest that mast cells play an important role in the regulation of angiogenesis in OSCC, although there are aspects of their activity of potential diagnostic and therapeutic significance which require further research.
\end{abstract}

Key words: OSCC, mast cells, microvessels, angiogenesis.

\section{Introduction}

Shortly after being identified by Paul Ehrlich in the $19^{\text {th }}$ century [1], mast cells were found around margins of developing tumors [2]. From the very beginning the presence of mast cell infiltrates near to the interface between neoplastic and unaffected tissues was suspected not to be incidental and many further studies revealed their influence on tumor behavior.

Until now, the role of mast cell accumulation has been evaluated in a number of tumors, such as oral malignant and premalignant lesions, [3-7], carcinomas of the stomach [8], colon, [9], liver [10], breast [11], endometrium [12], cervix [13, 14], prostate [15], nonsmall cell pulmonary carcinomas [16], neoplasms of vascular origin [17], Hodgkin lymphomas [18], basal cell carcinomas [19] and melanocytic skin lesions [20]. Mast cells are considered to interact with various neoplasms, significantly affecting their growth, progress and capability to metastasize [21]; however, it is still a poorly investigated area and drawing conclusions on the actual, often compound, role of these cells requires particular care. First of all, mast cells are not the only components of the complex tumor microenvironment [22]. Secondly, despite their participation in supporting cancer progression, they also present additional anticancerous activity [23]. Finally, they consist of different subpopulations which may exert diverse effects on cancer cells [24].

Mast cell activity facilitating tumorigenesis includes production of factors that support the process of forming a new vascular system within the site of neo- 
plastic involvement. Mast cell accumulation tends to correlate with increasing density of microvessels [2]. Taking into account the significance of angiogenesis for tumor development and progression [25], proangiogenic activity of mast cells has been recognized as preponderant.

Remarkably, mast cells in various neoplasms and sites may behave differently and the differences between their role in peritumoral and intratumoral regions are currently being assessed [20, 23].

The aim of the present study was to evaluate the microvessel density and mast cell concentration in peritumoral and intratumoral regions of OSCC, the most frequent among all malignant tumors derived from oral mucosa. Another purpose of this research was to find the possible relationship between these parameters.

\section{Material and methods}

\section{Tissue samples}

We examined 47 formalin-fixed and paraffin-embedded specimens of OSCC obtained from patients who underwent surgical treatment in the Department of Cranio-Maxillofacial and Oncological Surgery. 26 cases were from males and 21 from females. The mean age of patients was 55 years. There were selected samples of well (27), moderately (16) and poorly differentiated (4) OSCC. Additionally, tissue specimens from 12 cases of uninvolved oral mucosa were chosen as controls.

\section{Immunohistochemistry}

Mast cells and microvessels were identified by immunohistochemical detection of tryptase and CD-31, respectively. Paraffin sections were mounted onto $\mathrm{Su}-$ perFrost slides, deparaffinized with xylene, then treated in a microwave oven in a Target Retrieval Solution (Dako, TRS, pH 6.0) for 20 minutes $(2 \times 5$ minutes

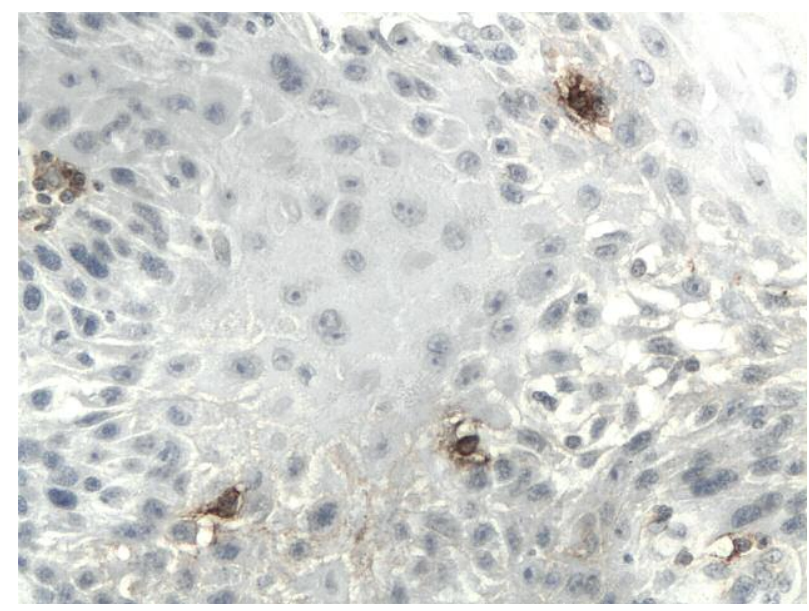

Fig. 1. Tryptase-positive mast cells in intralesional region of OSCC, original magnification $200 \times$ at $360 \mathrm{~W}$ and $2 \times 5$ minutes at $180 \mathrm{~W})$ and transferred to distilled water. Endogenous peroxidase activity was blocked by $0.3 \%$ hydrogen peroxide in distilled water for 30 minutes, and then sections were rinsed with Tris-buffered saline (TBS, Dako, Denmark) and incubated for 30 minutes in the humid chamber with monoclonal mouse anti-human: CD31 Endothelial Cell (Dako, clone JC70A, dilution $1: 25$ ) and Mast Cell Tryptase (Dako, clone AA1, dilution: 1 : 50). Afterwards EnVision+System-HRP (Dako, Denmark) prepared according to the instructions of the manufacturer was used. Visualization was performed by incubating the sections in a solution of 3,3'-diaminobenzidine (Dako, Denmark). After washing, the sections were counter-stained with hematoxylin and coverslipped.

For each antibody and for each sample a negative control was processed. Negative controls were carried out by incubation in the absence of the primary antibody and always yielded negative results.

\section{Morphometry}

Histological morphometry was performed by means of an image analysis system consisting of a PC equipped with a Pentagram graphical tablet, Indeo Fast card (frame grabber, true-color, real-time), produced by Indeo (Taiwan), and Panasonic color TV camera (Japan) coupled to a Carl Zeiss microscope (Germany). This system was programmed (MultiScan 8.08 software, produced by Computer Scanning Systems, Poland) to calculate the number of objects (semiautomatic function). The colored microscopic images were saved serially in the memory of a computer, and then quantitative examinations were carried out. In squamous cell carcinoma specimens, intralesional and perilesional counts were performed. For the intralesional count the tryptase positive mast cells (Fig. 1) and CD31 positive microvessels (Fig. 2) were determined by recording all positive cells or vessels (semiautomatic function) in a se-

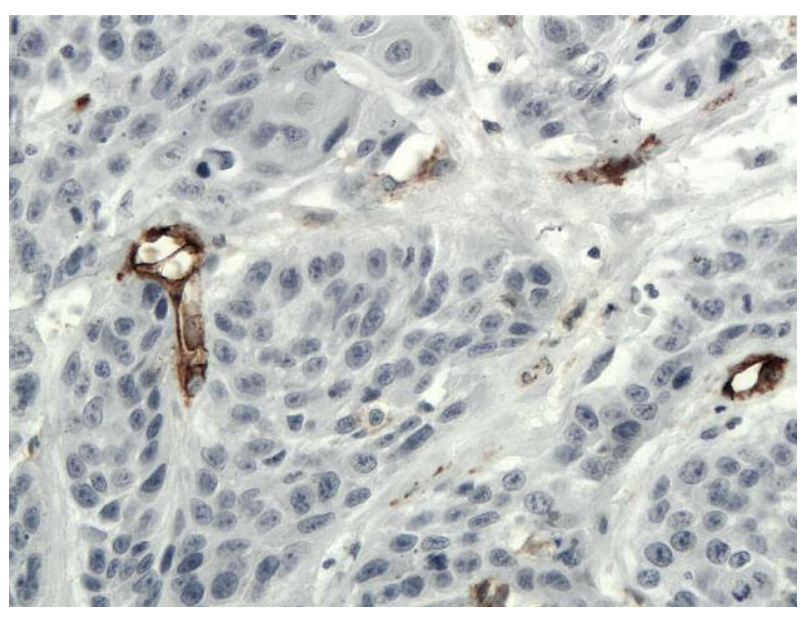

Fig. 2. CD31-positive microvessels in intralesional region of OSCC, original magnification $200 \times$ 


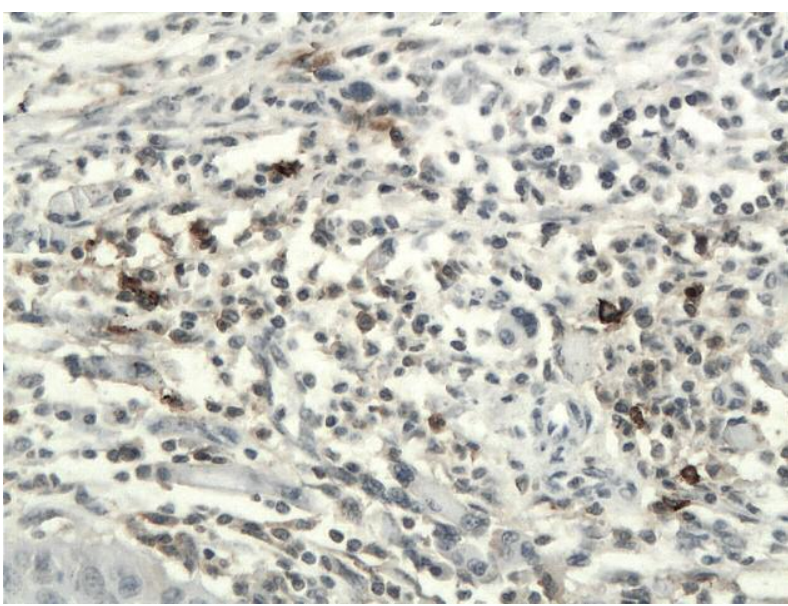

Fig. 3. Tryptase-positive mast cells in perilesional region of OSCC, original magnification $200 \times$

quence of 5-7 consecutive computer images of $400 \times$ high power fields $-0.0047 \mathrm{~mm}^{2}$ each. Mast cells were scored positive when displayed cytoplasmic granules stained positively with anti-tryptase monoclonal antibody. In CD31 positive microvessels the vessel lumen, although usually present, was not a criterion used to define a microvessel. For the perilesional count the same method was used. The perilesional region was defined as described earlier [20]. Briefly, only the fields of view along the interface between the lesion and its neighborhood were chosen (Fig. 3, 4). The results were expressed as the mean number of immunopositive cells or vessels per $\mathrm{mm}^{2}$.

\section{Statistical methods}

All values were expressed as the mean $\pm \mathrm{SD}$ (standard deviation). Differences between groups were tested using unpaired Student's t-test preceded by evaluation of normality and Levene's test. The Mann-Whitney $\mathrm{U}$ test was used where appropriate. Correlation coefficients were calculated using Spearman's method. Results were considered statistically significant if $\mathrm{p}<0.05$.

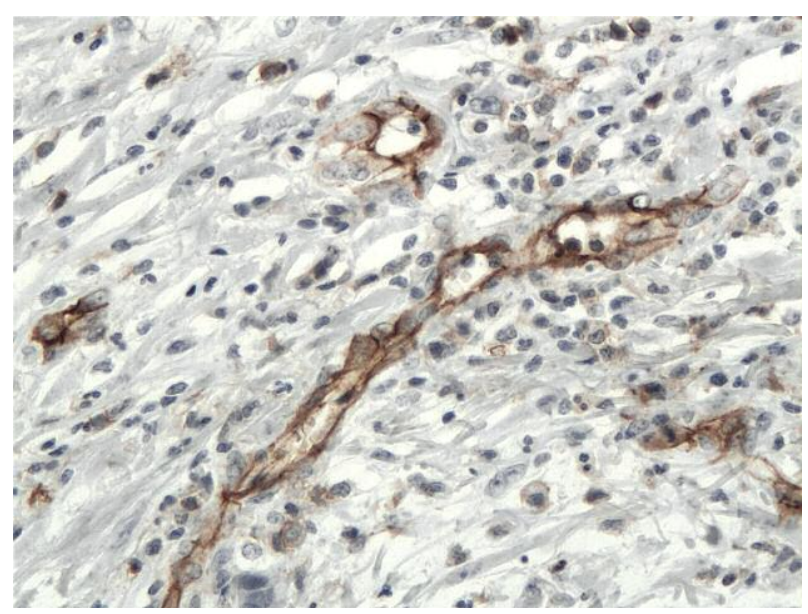

Fig. 4. CD31-positive microvessels in perilesional region of OSCC, original magnification $200 \times$

\section{Results}

The quantitative data of mast cell infiltrates and microvessel density in OSCC and controls are summarized in Table I. The tryptase positive mast cells and microvessels were in OSCC more numerous in the perilesional region than in intralesional localization; however, this difference as regards microvessels was not significant. Both tryptase positive mast cells and microvessel density were in OSCC in both localizations significantly increased as compared to controls. In OSCC in both localizations there were significant positive correlations between tryptase positive mast cells and microvessel density. In controls this correlation was positive, but did not reach statistical significance (Table II).

\section{Discussion}

The results of our study showed a significant positive correlation between mast cell concentration and microvessel density within and around OSCC, suggesting a relevant influence of mast cells on angiogenesis in this neoplasm. The density of intralesional and perilesional mast cell accumulation differed in favor of the latter; however, the slight difference between intra-

Table I. Quantitative data of mast cell infiltrates and microvessel density in oral squamous cell carcinoma (OSCC) and controls

\begin{tabular}{lcccc}
\hline TryptaSe Positivity & $\begin{array}{c}\text { OSCC - INTRALESIONAL } \\
\text { COUNT }(\mathbf{N}=47)\end{array}$ & $\begin{array}{c}\text { OSCC }- \text { PERILESIONAL } \\
\text { COUNT }(\mathbf{N}=47)\end{array}$ & $\begin{array}{c}\text { CONTROLS } \\
(\mathbf{N}=12)\end{array}$ & P-VALUE* $^{*}$ \\
\hline cells $\left(\right.$ per $\left.1 \mathrm{~mm}^{2}\right)$ & $87.7 \pm 29.3$ & $113.7 \pm 52.1$ & $27.3 \pm 9.8$ & $\begin{array}{c}<0.004^{\mathrm{a}},<0.001^{\mathrm{b}}, \\
<0.001^{\mathrm{c}}\end{array}$ \\
\hline $\begin{array}{l}\text { Cd31 positive micro- } \\
\text { vessels }\left(\text { per } 1 \mathrm{~mm}^{2}\right)\end{array}$ & $90.5 \pm 32.4$ & $104.9 \pm 38.2$ & $41.9 \pm 17.9$ & $=0.051(\mathrm{NS})^{\mathrm{a}}$, \\
\hline
\end{tabular}

abetween intralesional and perilesional count

between intralesional count and controls

cbetween perilesional count and controls

NS - not significant 
Table II. Spearman rank order correlations between tryptase positive mast cells and microvessel density in oral squamous cell carcinoma (OSCC) and controls

\begin{tabular}{ll}
\hline GROUPS & TRYPTASE POSITIVE MAST CELLS VERSUS MICROVESSEL DENSITY \\
\hline OSCC - intralesional count $(\mathrm{n}=47)$ & $\mathrm{r}=-0.34, \mathrm{p}<0.02$ \\
\hline OSCC - perilesional count $(\mathrm{n}=47)$ & $\mathrm{r}=-0.47, \mathrm{p}<0.001$ \\
\hline Controls $(\mathrm{n}=12)$ & $\mathrm{r}=0.41, \mathrm{p}=0.18(\mathrm{NS})$ \\
\hline NS - not significant &
\end{tabular}

tumoral and peritumoral CD31-positive microvessel density was of no statistical significance.

Tumorigenesis of OSCC is a multistep event which includes accumulation of genetic alterations and an environmental impact [26]. The increase of tumor aggressiveness is at least partially based on the complex process of forming a new vascular system providing it with oxygen supply. It is commonly accepted that angiogenesis, though not completely clarified yet, has profound significance for the growth of cancers, as well as their potential to invade surrounding tissues and metastasize [25]. The tumor microenvironment, affecting neovascularization, consists of several groups of components including mast cells [22]. Although the mast cell is only one of many participants in the compound network of factors controlling angiogenesis, its role may emerge as preponderant. However, trying to elucidate it, we encounter difficulties which stem from the ambiguous behavior of these cells, their heterogeneity and inconvenient methods of visualization.

Routine staining may lead to misinterpretation and often does not reveal all the mast cells in examined specimens. Histochemical techniques (toluidine blue staining) partially reduce the risk of erroneous assessment, but the best method to identify mast cells seems to be immunohistochemical staining. However, immunohistochemical examination revealed that the population of mast cells around the tumor is not homogeneous. In some cells tryptase and chymase expression were observed, while others expressed only tryptase, which allows us to distinguish two subpopulations of potentially divergent biological influence on the neoplasm [20, 23].

In our research we used tryptase as a marker of both subpopulations and focused on the total number of mast cells in particular areas.

Another difficulty in evaluating the role of mast cells is connected with their presence and active participation in several, apart from tumorigenesis, physiological and pathological events, including reactions of immediate hypersensitivity. They are capable of processing antigens, phagocytosis, as well as producing and releasing biologically active factors, and, moreover, their surface is covered with many receptors and molecules reacting with various kinds of stimuli. Unfortunately, no human or animal model of a condition with an absolute lack of mast cells, which could help us understand their functions, has been recognized yet [1].
Studies concerning the influence of mast cells on cancer progression also revealed their anti-cancerous activity. According to the literature of the subject pro-cancerous activity of mast cells comprises stimulation of angiogenesis, tissue remodeling and modulating the response of the immune system. Mast cell proangiogenic factors include vascular endothelial growth factor, basic fibroblast growth factor, transforming growth factor $\beta$ (TGF- $\beta$ ), tumor necrosis factor $\alpha$ (TNF- $\alpha)$, interleukin 8 (IL-8), metalloproteinases, tryptase and chymase. Some of above-mentioned factors (tryptase, chymase, TNF- $\alpha$ ) may also cause opposite effects. Other anti-cancerous mediators released by mast cells are IL-1 and IL-6. The role of some mediators is dependent on their concentration, access to other agents and the site of mast cell accumulation [23].

A number of studies reveal a significant positive correlation between the increase of mast cell and microvessel density, features of tumor aggressiveness and poor clinical outcomes [25, 27-29]. It is intriguing that some research conducted into this field does not confirm this tendency, suggesting that in particular cases mast cell density in poorly differentiated cancers may be lower than in well-differentiated ones [8] or that mast cell concentration in premalignant and malignant lesions may be decreased in comparison to unaffected tissues [7].

The results of our study confirmed the intense association between the presence of mast cells and the process of angiogenesis near and within the tumor defined as the increase in microvessel density revealed in the slides by using an immunohistochemical method of staining endothelial cells with anti-CD-31 antibody.

Another matter taken recently into consideration is the difference between mast cell concentration in perilesional and intralesional sites and its potential significance for tumor development. It is suggested in the literature that the number of peritumoral mast cells seems to be increased in comparison to the number of their intratumoral counterparts [23]. In our study, the density of mast cells in perilesional and intralesional regions significantly differed, but no significant difference between perilesional and intralesional microvessel density was observed. Although the obtained results confirm the influence of increased mast cell concentration on angiogenesis in intralesional and perilesional regions of OSCC, they do not clearly support the suggestion that mast cell behavior and influence on an- 
giogenesis vary depending on its localization, leaving this area for further research.

Oral cancer is the sixth most frequent malignant neoplasm worldwide. Squamous cell carcinoma comprises the considerable majority of cases, although other histological types may also appear in that site [30]. Adverse prognosis and still poor survival rate in spite of improvements in therapy [31] require our attention to be focused on yet unexplained aspects of development and progression of OSCC in the hope of setting new therapeutic targets.

As some studies bring ambiguous conclusions, evaluation of the undoubtedly considerable role of mast cells in the development of OSCC and other malignant neoplasms seems vitally important as it may considerably alter the diagnostic and therapeutic approach. Another implication is that the influence of mast cells on tumors is particularly complex and in a number of cases still difficult to predict, which suggests that other factors may participate in this process and modify it.

The authors declare no conflict of interests.

Medical University of Lodz grant no. 502-03/6-03801/502-64-048

\section{References}

1. Metcalfe DD, Baram D, Mekori YA. Mast cells. Physiol Rev 1997; 77: 1033-1079.

2. Maltby S, Khazaie K, McNagny KM. Mast cells in tumor growth: angiogenesis, tissue remodeling and immune-modulation. Biochim Biophys Acta 2009; 1796: 19-26.

3. Cheema VS, Ramesh V, Balamurali PD. The Relevance of Mast Cells in Oral Squamous Cell Carcinoma. J Clin Diagn Res 2012; 6: 1803-1807.

4. Gholamreza J, Mehdi S. Comparative immunohistochemical analysis of angiogenesis and mast cell density in oral normal mucosa and squamous cell carcinoma. Dent Res J (Isfahan) 2012; 9: 8-12.

5. Kalra M, Rao N, Nanda K, et al. The role of mast cells on angiogenesis in oral squamous cell carcinoma. Med Oral Patol Oral Cir Bucal 2012; 17: 190-196.

6. Sharma B, Sriram G, Saraswathi TR, Sivapathasundharam B Immunohistochemical evaluation of mast cells and angiogenesis in oral squamous cell carcinoma. Indian J Dent Res 2010; 21: $260-265$

7. Michailidou EZ, Markopoulos AK, Antoniades DZ. Mast cells and angiogenesis in oral malignant and premalignant lesions. Open Dent J 2008; 2: 126-132.

8. Ribatti D, Guidolin D, Marzullo A, et al. Mast cells and angiogenesis in gastric carcinoma. Int J Exp Pathol 2010; 91: 350356.

9. Lachter J, Stein M, Lichtig C, et al. Mast cells in colorectal neoplasias and premalignant disorders. Dis Colon Rectum 1995 38: 290-293.

10. Terada T, Matsunaga Y. Increased mast cells in hepatocellular carcinoma and intrahepatic cholangiocarcinoma. J Hepatol 2000; 33: 961-966.

11. della Rovere F, Granata A, Familiari D, et al. Mast cells in invasive ductal breast cancer: different behavior in high and minimum hormone-receptive cancers. Anticancer Res 2007; 27: 2465-2472.
12. Ribatti D, Finato N, Crivellato E, et al. Neovascularization and mast cells with tryptase activity increase simultaneously with pathologic progression in human endometrial cancer. Am J Obstet Gynecol 2005; 193: 1961-1965.

13. Benítez-Bribiesca L, Wong A, Utrera D, Castellanos E. The role of mast cell tryptase in neoangiogenesis of premalignant and malignant lesions of the uterine cervix. J Histochem Cytochem 2001; 49: 1061-1062.

14. Graham RM, Graham JB. Mast cells and cancer of the cervix. Surg Gynecol Obstet 1996; 123: 3-9.

15. Johansson A, Rudolfsson S, Hammarsten P, et al. Mast cells are novel independent prognostic markers in prostate cancer and represent a target for therapy. Am J Pathol 2010; 177: 1031-1041.

16. Carlini MJ, Dalurzo MCL, Lastiri JM, et al. Mast cell phenotypes and microvessels in non-small cell lung cancer and its prognostic significance. Hum Pathol 2010; 41: 697-705.

17. Glowacki J, Mulliken JB. Mast cells in hemangiomas and vascular malformations. Pediatrics 1982; 70: 48-51.

18. Molin D, Edström A, Glimelius I, et al. Mast cell infiltration correlates with poor prognosis in Hodgkin's lymphoma. $\mathrm{Br}$ J Haematol 2002; 119: 122-124.

19. Erkiliç S, Erbağci Z. The significance of mast cells associated with basal cell carcinoma. J Dermatol 2001; 28: 312-315.

20. Dyduch G, Okoń K, Pescarini E. Mast cells in melanocytic skin lesions. An immunohistochemical and quantitative study. Pol J Pathol 2011; 3: 139-144.

21. Conti P, Castellani ML, Kempuraj D, et al. Role of mast cells in tumor growth. Ann Clin Lab Sci 2007; 37: 315-322.

22. Swartz MA, Iida N, Roberts EW, et al. Tumor microenvironment complexity: emerging roles in cancer therapy. Cancer Res 2012; 72: 2473-2480.

23. Dyduch G, Kaczmarczyk K, Okoń K. Mast cells and cancer: enemies or allies? Pol J Pathol 2012; 63: 1-7.

24. Varela MS, Mauro L, Puricelli L, et al. Prognostic relevance of tryptase and chymase positive mast cells and neoangiogenesis in colorectal carcinomas J Clin Oncol 2004; 22: 3745.

25. Folkman J. The role of angiogenesis in tumor growth. Semin Cancer Biol 1992; 3: 65-71.

26. Choi S, Myers JN. Molecular pathogenesis of oral squamous cell carcinoma: implications for therapy. J Dent Res 2008; 87: 1432

27. Kyzas PA, Stefanou D, Batistatou A, et al. Prognostic significance of VEGF immunohistochemical expression and tumor angiogenesis in head and neck squamous cell carcinoma. J Cancer Res Clin Oncol 2005; 131: 624-630.

28. Pazouki S, Chisholm DM, Adi MM, et al. The association between tumour progression and vascularity in the oral mucosa. J Pathol 1997; 183: 39-43.

29. Weidner N, Semple JP, Welch WR, et al. Tumor angiogenesis and metastasis-correlation in invasive breast carcinoma. N Engl J Med 1991; 324: 1-8.

30. Zini A, Czerninski R, Sgan-Cohen HD. Oral cancer over four decades: epidemiology, trends, histology, and survival by anatomical sites. J Oral Pathol Med 2010; 39: 299-305.

31. Howell GM, Grandis JR. Molecular mediators of metastasis in head and neck squamous cell carcinoma. Head Neck 2005; 27: 710-717.

\section{Address for correspondence}

Lukasz Pyziak

Department of Nephropathology

Medical University of Lodz

Czechosłowacka 8/10

92-216 Lodz, Poland

tel. +48426757622

fax +48426790191

e-mail: lukasz.pyziak@umed.lodz.pl 